\title{
Anxiety and Depression in Alcohol Dependence Syndrome
}

\author{
M Lekshmy ${ }^{1}$, R Mohanambal ${ }^{2}$
}

\begin{abstract}
The average alcohol dependent person decreases his life span by 10 to 15 years. Alcohol dependent individuals are significantly more emotional, frequently more anxious and/ or depressed, more moody and tense. The evidences suggest that the presence of increased levels of depression and anxiety in these patients is likely to influence treatment process and outcomes. The objectives were to measure and correlate the level of anxiety and depression among the newly diagnosed alcohol dependent individuals and to identify the relationship of anxiety and depression with the selected bio psychosocial factors. Materials and Methods: A Cross sectional descriptive survey was done from Sep to Nov 2014, among 60 newly diagnosed alcohol dependent patients, who were admitted at a tertiary care centre in Kolkata. Data collected using a semi structured interview schedule for assessing the Bio psychosocial variables and standardized scales for identifying the Level of anxiety (STAI -Y1\&2), depression (MADRS) and alcohol abuse or dependence (AUDIT). Purposive sampling technique was adopted, and the data was analysed by descriptive and inferential statistics. Result: Mean age of the subjects was 36.53 (SD \pm 7.63$)$. Half (55\%) of the group gave the family history of alcoholism and $48 \%$ were drinking alcohol for more than 10 years. Physiological complications and co-morbidity were present in 63\%. Most of the subjects had moderate level of state (66.7\%) and trait $(62 \%)$ anxiety with a mean score of $43.67(S D \pm 6.68)$ and $40.88(S D \pm 5.675)$ respectively. Majority (80\%) of them experienced mild depression with mean score of 11.23 (SD \pm 5.398 ). There was significant correlation between the level of anxiety and depression (p<0.001). However, most of the bio-psychosocial variables did not show significant relationship with level of anxiety and depression. Duration of alcohol drinking was related with moderate level of trait anxiety $(p<0.05)$. The subjects with physiological complication of alcohol abuse or with a co morbidity showed increased level of state anxiety (p<0.05). It was also noted that family member's chronic illness contributed to increased depression in them $(p<0.05)$. Conclusion: The study findings indicate that the newly diagnosed alcohol dependent subjects experience an increased level of anxiety and depression with a significant correlation between the two disorders. Few bio psychosocial factors, such as duration of alcohol consumption, physiological complications and co morbidity and family member's illness may contribute towards increased levels of anxiety and or depression
\end{abstract}

Keywords: Patients with Alcohol Dependence Syndrome, Anxiety, Depression, Bio-psychosocial factors and Newly diagnosed patient

\section{Introduction}

India has always been described as an abstinent culture by the uninformed however alcohol use is widespread and social attitudes are more ambient than negative. The hazards associated with drinking are also known since ancient times, but only in recent years, it has been acknowledged as a human and a public health problem. The initiation and continuation of alcohol use by an individual is influenced by numerous factors, chiefly the individual's genetic makeup, the environments to which he or she is exposed, and complex mechanisms through which genes interact with one another and with the environment. These same factors determine an individual's pattern of alcohol consumption and the risks for developing alcohol dependence or other alcohol use disorders. Failure to curb the problems rigorously and early in course of the disease increases risks of adverse outcomes in terms of physical, mental and social wellbeing. World health organization estimates that the harmful use of alcohol results in 2.5 million deaths each year. Alcohol is causal factor in 60 types of disease and injuries and a component cause in 200 others. Alcohol dependence, especially severe current dependence, is a risk factor for unfavourable course of depressive and/or anxiety disorders. Alcohol use related problems and depressive symptoms have reciprocal, positive effect on each other.Studies in the general population show that persons with anxiety or depressive disorders have a 2 to 3 fold increased risk of alcohol use disorders. Persons with this co morbid condition suffer from more severe impairment, more suicidality and poorer treatment outcomes.

\section{Background of the Study}

One way that people may choose to cope with stress is by turning to alcohol. Drinking may lead to positive feelings and relaxation, at least in the short term. However, problems arise when stress is on-going and people continue to try and deal with its effects by drinking alcohol, instead of "calming the nerves," long-term heavy drinking can actually work against the individual, leading to a host of medical and psychological problems and increasing the risk for alcohol dependence. According to DSM-IV criteria depressive disorder is characterized by depressed mood and/or loss of interest and pleasure in normally enjoyable activities for at least two weeks in combination with other symptoms such as changes in appetite and weight, changes in sleep and activity, lack of energy, feelings of guilt, problems with thinking and making decisions, and recurring thoughts of death or suicide. Alcohol being a brain depressant, symptoms of severe depression is common among patients, who consume alcohol in larger amount and may be labelled as alcohol induced mood disorder. Further evidence suggests that the most causal association between alcohol use disorder and moderate depression is one in which alcohol use disorder increases the risk of moderate depression, rather than vice-versa.

Anxiety is a vague sense of apprehension that is accompanied by feelings of uncertainty, helplessness, isolation, and insecurity. Anxiety disorders are the most common psychiatric disorders in the United States, affecting $15 \%$ to $25 \%$ of the total population. The National Epidemiologic survey on Alcohol and related conditions conducted by the National institute on alcohol abuse and 


\section{International Journal of Science and Research (IJSR) \\ ISSN (Online): 2319-7064}

Index Copernicus Value (2015): 78.96 | Impact Factor (2015): 6.391

alcoholism shows that about $20 \%$ of persons with a current substance use disorder experience a mood or anxiety disorder within the same period. The relationship between anxiety and alcohol can be described using the concept of co morbidity, which can be defined as diagnosable, problematic alcohol use and anxiety symptoms that are both present at some point in a person's life time, but not necessarily at the same time. Alcohol use, in an attempt to reduce anxiety (self medication hypothesis) has often been used as an explanation for the high co morbidity rate between anxiety, depression and alcohol use disorders. Anxious individuals may resort to alcohol to decrease feelings of anxiety, which might be an effective strategy in the short term, providing reinforcement for this pattern. However, alcohol, and especially withdrawal from alcohol, increases anxiety-like symptoms in the longer run via physiological mechanisms such as kindling. Alcohol may also worsen anxiety levels because of the negative familial, social or occupational consequences of heavy drinking. Individuals will then increase their drinking behaviour in an attempt to alleviate these worsening feelings of anxiety because drinking has become a learned strategy for dealing with these symptoms. Anxiety and depression are highly co morbid with alcohol dependence, and they are usually more severe when they co occur than when they present alone. Alcohol use disorders have a negative effect on the course of anxiety and depressive disorders. Therefore, it is essential to identify which depressed or anxious persons are at increased risk of having alcohol use disorders.

There is a high risk of developing alcoholism (specifically of the early-onset type, developing before 25 years of age) for individuals with a significant family history of alcoholism. This vulnerability is also found to be linked to early childhood influences in stressful environments that might include poverty, violence, family conflict and poor parenting. Many genetic studies establish that Alcohol Dependence aggregates in families, and twin studies show a higher concordance in monozygotic than dizygotic twins, with an estimated heritability of about $50 \%$. The prevalence of alcohol misuse is heaviest in adolescents and young adults whereas, it is lower in those aged over 45 years. The followers of certain religions which proscribe alcohol, such as Islam, Hinduism, and the Baptist Church, are less likely than the general population to misuse alcohol. The risk of alcohol misuse is much increased among men who have easy access to alcohol Lower socioeconomic status and educational levels result in a greater risk of alcohol related death, disease and injury. Marital status (unmarried/divorced), family history of alcohol use and caste has its significance in the onset of alcohol use.

In India, very few studies are conducted to assess the level of anxiety and depression among people diagnosed as Alcohol dependent syndrome. The aim of the study was to assess the level of anxiety and depression among the subjects who were admitted in the hospital. The study included sixty male patients admitted to the hospital for treatment of alcohol dependence and excluded those with history of multiple substance abuse other than alcohol/tobacco, co morbidity of other mental disorders and Medical illness that may significantly influence CNS function or structure,

\section{Description of the tool}

A semi structured questionnaire was used to collect the relevant demographic and bio psychosocial data. This included age, religion, residence, literacy, marital status, income, family history of alcohol consumption, duration of drinking, physiological complications and co-morbidity, presence of social/family stressors such as nature of job, number of dependent members, family member's illness. Standardized tools such as AUDIT, State-Trait Anxiety Inventory (STAI) and Montgomery- ̊sberg Depression Rating Scale (MADRS) were used to measure Alcohol abuse and dependence, level of Anxiety and Depression.

\section{Methodology}

A non experimental cross sectional survey method was used for the study. A total of sixty subjects fulfilling inclusion criteria and the ICD-10 criteria for alcohol dependence syndrome who are admitted to the tertiary care hospital for treatment were selected by purposive sampling technique. The ethical clearance from the institution and consent from the subjects were obtained well in advance. The Statistical Package for Social Sciences Version-20 was used for the analysis of data. Percentage, chi-square test, Kruskal Wallis Test, Mann-Whitney U test and correlation were used for data analysis.

\section{Result}

The sample consisted of a total of 60 participants. Table I shows distribution of sample in terms of Bio-psychosocial variables. Out of total study samples about $43 \%$ subjects belong to the age group of 30-39 years. The mean age of the study samples were 36.53 ( $\mathrm{SD} \pm 7.63$ ) similar to the findings of Benegal et al (2002) in Bangalore, which observed that the mean age of development of significant alcohol dependence dropped to 29 years from 35 years in the ten year period of 1988 to 1998 . However Kumar et al (2010) reported that the mean age of onset of alcoholism was 28.3years. Most of them (68\%) were Hindus and about $60 \%$ of samples were from rural area. The findings are in consistent with the study findings of Girish et al. This study revealed that $60 \%$ subjects were Hindus. Nearly half (45\%) of rural population were very frequent users as against users in town $(23 \%)$ or slum $(20 \%)$. It is observed that half of the subjects $(50 \%)$ were educated up to secondary level whereas a study by Gururaj et al (2006a) indicated greater use of alcohol among those with education level less than 8 grades $(85 \%)$. However this may be because the subjects belonged to a homogenous group of serving soldiers who are inducted in service with minimum educational qualification above $8^{\text {th }}$ grade. It is also observed that maximum (82 \%) subjects were married but $62 \%$ of them were living alone away from their families, which can be compared with the findings of the National survey conducted in Finland (2000-2001) among 3573 alcohol dependent individuals,. The survey result shows that cohabiting and living alone are associated with heavy drinking and alcohol dependence. A study by Meena et al (2002) among the urban population of Rohtak city showed more alcohol use among married men, similar to the findings observed by Ghulam et al (1996) \& Singh et 


\section{International Journal of Science and Research (IJSR) \\ ISSN (Online): 2319-7064}

Index Copernicus Value (2015): 78.96 | Impact Factor (2015): 6.391

al (2000). Whereas Hazarika et al (2000) reported that alcohol use was generally higher in the unmarried population. Majority (78\%) of the subjects were unskilled workers, which is similar to the findings of Reddy et al (2010).. Ghulam et al (1996) from Rajasthan observed that up to $45 \%$ of the labour classes were involved in heavy drinking. Whereas Hazarika et al (2000) noticed that $51 \%$ of those employed in service and in business categories consumed alcohol in excess. Chaturvedi et al (2003) from Arunachal Pradesh reported that majority of self-employed men engaged in agriculture and other day-to-day activities were consuming more alcohol, possibly as a source of constant energy and relaxation.

Table 1: Bio psychosocial variables $n=60$

\begin{tabular}{|c|c|c|c|c|c|}
\hline $\begin{array}{c}\text { S } \\
\text { No }\end{array}$ & \multicolumn{3}{|c|}{ Bio psychosocial variables } & $\begin{array}{c}\text { Frequency } \\
\text { (f) }\end{array}$ & $(\%)$ \\
\hline \multirow[t]{4}{*}{1} & \multirow{4}{*}{$\begin{array}{l}\text { Age (in } \\
\text { years) }\end{array}$} & \multicolumn{2}{|l|}{$20-29$} & 14 & 23.3 \\
\hline & & \multicolumn{2}{|l|}{$30-39$} & 26 & 43.3 \\
\hline & & \multicolumn{2}{|l|}{$40-49$} & 17 & 28.3 \\
\hline & & \multicolumn{2}{|l|}{$>=50$} & 3 & 5.0 \\
\hline \multirow[t]{4}{*}{2} & \multirow[t]{4}{*}{ Religion } & \multicolumn{2}{|l|}{ Hindu } & 41 & 68.3 \\
\hline & & \multicolumn{2}{|c|}{ Christian } & 13 & 21.7 \\
\hline & & \multicolumn{2}{|c|}{ Muslim } & 3 & 5.0 \\
\hline & & \multicolumn{2}{|l|}{ Sikh } & 3 & 5.0 \\
\hline \multirow[t]{2}{*}{3} & \multirow[t]{2}{*}{ Residence } & \multicolumn{2}{|l|}{ Rural } & 36 & 60.0 \\
\hline & & \multicolumn{2}{|l|}{ Urban } & 24 & 40.0 \\
\hline \multirow[t]{4}{*}{4} & \multirow[t]{4}{*}{ Literacy } & \multicolumn{2}{|c|}{ Primary } & 4 & 6.7 \\
\hline & & \multicolumn{2}{|c|}{ Secondary } & 30 & 50.0 \\
\hline & & \multicolumn{2}{|c|}{ Higher secondary } & 24 & 40.0 \\
\hline & & \multicolumn{2}{|c|}{ Graduation \& above } & 2 & 3.3 \\
\hline \multirow[t]{4}{*}{5} & \multirow{4}{*}{$\begin{array}{l}\text { Marital } \\
\text { status }\end{array}$} & Married & & 12 & 20.0 \\
\hline & & Unmarrie & & 10 & 16.7 \\
\hline & & \multicolumn{2}{|c|}{ Separated/divorced } & 1 & 1.7 \\
\hline & & \multicolumn{2}{|c|}{ Living alone (married) } & 37 & 61.7 \\
\hline 6 & Nature of job & General(unsk & lled) & 47 & 78.3 \\
\hline & & Technical(sk & led) & 13 & 21.7 \\
\hline 7 & Income & $20000-290$ & & 23 & 38.3 \\
\hline & (in Rs per & $30000-390$ & & 28 & 46.7 \\
\hline & month) & $40000-490$ & & 9 & 15.0 \\
\hline 8 & Number of & Nil & & 1 & 17 \\
\hline & Dependents & $1-2$ & & 6 & 10.0 \\
\hline & & $3-4$ & & 37 & 61.7 \\
\hline & & $\geq 5$ & & 16 & 26.7 \\
\hline 9 & Family & No & & 27 & 45.0 \\
\hline & $\begin{array}{l}\text { history of } \\
\text { drinking }\end{array}$ & Yes & & 33 & 55.0 \\
\hline 10 & Duration of & 6 Months - 5 & ears & 12 & 20.0 \\
\hline & drinking & 5 Years-10 & ears & 23 & 38.3 \\
\hline & & $>10 \mathrm{Yea}$ & & 25 & 41.7 \\
\hline 11 & Physic & ogical compli- $\mathrm{N}$ & & 22 & 36.7 \\
\hline & cations & \&co-morbidity Y & & 38 & 63.3 \\
\hline 12 & Family memb & r suffering from & No & 45 & 75.0 \\
\hline & chron & c illness & Yes & 15 & 25.0 \\
\hline
\end{tabular}

Another cohort study done by Head J et al (1985-91) on working men at different London offices revealed that a stressful psychosocial work environment in terms of effectreward imbalance was found to be a risk factor for Alcohol Dependence in men. Out of the total subjects, $47 \%$ were having a monthly family income of Rs 30000-39000, and $62 \%$ of them were having 3-4 dependent family members. Gururaj et al (2006a) reported greater use of alcohol among those who had lower and medium levels of income $(<6000$ in 84\%). The studies by Reddy et al. (2010) and Vohra et al. indicated that alcohol dependence was more common among low socio economic class. The family history of alcoholism was seen in $55 \%$ of the subjects, which is similar to the study findings of Reshmi et al (2012) ,Sarkar et al,(2009), Sringeri et al (2008) and Mc Gue et al, (2006). In all these studies family history of alcoholism was significant among the subjects. The study shows that $48 \%$ of subjects were drinking alcohol for more than 10 years which is similar to the findings of the Bangalore study by Benegal et al (2002). They observed that majority $(72 \%)$ of them were taking alcohol for more than 5 years with an average of 10-12 years. Physiological complications and co-morbidity were present in most $(63.3 \%)$ of the subjects. study Gururaj et al (2006a) observed that alcohol users were three times at risk of suffering from a health problem $(\mathrm{OR}=2.8)$. Chronic alcohol users were more likely to perceive their health status as poor and the probability of reporting a bad health status was 2.5 (95\% CI: $1.5-3.8)$ times higher in comparison to non-users. It is noted in the present study that $25 \%$ of the subjects had a family member with chronic illness or disability. A comparison study of alcohol users versus nonusers by Gururaj et al. (2004), observed that for an alcohol user, the health status of the family and self is worse compared to non users. However no significant relationship was observed between selected bio psychosocial factors with AUDIT Score except for duration of drinking alcohol, which is similar to the findings of the Bangalore study (2002), the data revealed that majority $(72 \%)$ of people with alcohol dependence had been drinking for more than 5 years with an average of 10-12 years.

Table 2: Mean Anxiety and Depression Scores

$$
\mathrm{n}=60
$$

\begin{tabular}{|c|c|c|c|c|}
\hline Score & Min & Max & Mean & SD \\
\hline Anxiety state & 31 & 61 & 43.67 & 6.688 \\
\hline Anxiety trait & 27 & 56 & 40.88 & 5.675 \\
\hline Depression & 5 & 37 & 11.13 & 5.398 \\
\hline
\end{tabular}

Table 2 highlights that the mean score for state anxiety is 43.67 and for trait anxiety the mean score is 40.88 , indicating maximum number of subjects with moderate level of anxiety, whereas for depression they scored 11.13 indicating mild level of Depression. A study by Chaudhury et al among 100 alcohol dependent male subjects also revealed significantly higher scores for anxiety and depression (State Anxiety mean 51.3(SD \pm 1.3$)$, Trait anxiety $48.6(\mathrm{SD} \pm 10.7)$, Hamilton Rating Scale for Depression 9.37 ( $\mathrm{SD}_{ \pm} 3.9$ ). Another study by Sofia S F observed that $40 \%$ of subjects $(n=56)$ met the criteria for anxiety disorder and $14 \%(n=20)$ for depression. Also the individuals with anxiety symptoms were more likely to be depressed than those without the symptoms of anxiety $(\mathrm{p}<.001)$.

Table: 3 Correlations between State \& Trait Anxiety Scores

\begin{tabular}{|c|c|c|c|c|}
\hline \multicolumn{2}{|c|}{ Anxiety score Mean } & $\begin{array}{c}\text { Depression score } \\
\text { Mean }\end{array}$ & $\mathrm{r}$ & $\mathrm{P}$ Value \\
\hline State anxiety & 43.66 & & 0.708 & $<0.001$ \\
\hline Trait anxiety & 40.88 & 11.13 & 0.550 & $<0.001$ \\
\hline
\end{tabular}

with Depression Score $n=60$

\section{Volume 6 Issue 1, January 2017 www.ijsr.net}




\section{International Journal of Science and Research (IJSR) \\ ISSN (Online): 2319-7064}

Index Copernicus Value (2015): 78.96 | Impact Factor (2015): 6.391

Table 3 shows that there is significant correlation between state and trait anxiety scores with depression scores $(p<0.001)$. The r' value obtained for trait anxiety with depression scores (0.708) and state anxiety score with depression score (0.550).A similar study conducted at Moscow also suggested that the individuals with anxiety symptoms were more likely to be depressed than those without the symptoms of anxiety $(\mathrm{p}<.001)$. Another cross sectional survey conducted by Nomar et al (2007) in Brazil revealed twelve month prevalence for anxiety disorder was $15 \%$ and that for depressive disorders were $12 \%$. Symptom co-occurrence was more frequent for depression $(94 \%)$ followed by anxiety disorders (82\%). There was $74 \%$ proportion of anxiety symptoms among depressed and $61 \%$ proportion of depressive features among anxiety sufferers. Also the combination of depression plus anxiety was more prevalent.

Over all findings suggest that there is significant relationship between Level of anxiety and depression with biopsychosocial variables such as, Duration of alcohol drinking with Trait anxiety, Physiological complication and co morbidity with state anxiety and Family member's chronic illness with depression ( $\mathrm{p}<0.05)$. The study findings of Gururaj et al.(2004,2006) support the above findings. Their study observed that there is significant relationship of duration of drinking, physiological complications or co morbidity and family member's illness towards development of alcohol related problems among the subjects.

\section{Recommendation and Suggestions}

Interventional studies can be conducted to find out the effectiveness of various physical and psychological interventions to alleviate anxiety and depression among these patients. A self instructional module can be developed regarding identification of signs and symptoms of anxiety and depression and the remedial measures such as relaxation exercises, yoga, meditation etc.

\section{Conclusion}

The study findings indicate that the newly diagnosed alcohol dependent subjects, admitted in the hospital, experience an increased level of anxiety and depression with a significant correlation between the two disorders. Few bio psychosocial factors, such as duration of alcohol consumption, physiological complications and co morbidity and family member's illness may contribute towards increased levels of anxiety and or depression in these patients.

\section{References}

[1] Raju MSVK, Valdiya PA, Tampi UR, et al. Alcoholism in the Armed Forces. MJAFI. 2002; 58:149-51.

[2] Bangalore Project report on alcohol consumption patterns in India. Bangalore: NIMHANS; 2002.

[3] Global status report on alcohol. Geneva: World Health Organization; 2014.

[4] Alcohol report. Bangalore: NIMHANS; 2012.

[5] Katyal R, Bansal R, Goel K, Sharma S. Screening of the past alcohol users according to AUDIT, A cross sectional study in urban slum of Meerut. IJRRMS. 2013; 3:10-12.

[6] Anand K. Assessment of burden and surveillance of major non communicable diseases in India. New Delhi: World Health Organization (WHO) : South East Asia Regional Office: Workshop document; 2000

[7] Ray R. National survey on extent, pattern and trends of drug abuse in India. Ministry of Social Justice and Empowerment, New Delhi: Government of India and United Nations Office on Drugs and Crime; 2004.

[8] Indian Institute of Population Sciences and macro international, 2007. (NFHS-3). 2005-06: Mumbai: IIPS.

[9] Kushner MG,Abrams K, Borchardt C.The relationship between anxiety disorders and alcohol use disorders. Clin Psychol Rev 2000, Mar; 20 (2): 149-7.

[10] Anthenelli, R. (2010). Focus on Co morbid mental health disorders. Alcohol Research and Health; 23: 109117.

[11] Chaudhury S. Das SK. Mishra BS. Ukil B. Bhardwaj P. Dinker NL. Psychological assessment of alcoholism in males. Indian J Psychiatry. 2006; 48:114-117.

[12] Boschioo Lynn, Nicole Vogeizangs .Alcohol use disorders and the course of depressive and anxiety disorders. BJ Psychiatry. 2012; 200: 476-84.

[13] Vohra AK, Yadav BS, Khurana H. Study of Psychiatric co morbidity in alcohol dependence. Indian Journal of Psychiatry. 200; 459 (IV):247-50.

[14] Merikangas KR, Mehta RL, Molnar BE, Walters EE, Swendsen JD, Aguilar-Gaziola S, Bijl R, Borges G, 431 Caraveo- Anduaga JJ, DeWit DJ, Kolody B, Vega WA, Wittchen HU, and Kessler RC (1998). Co morbidity of substance use disorders with mood and anxiety disorders. Results of the international consortium in psychiatric epidemiology. Alcoholism Clinical and Experimental Research.1998; 23: 893-907.

[15] Mary W Kuria, David M, Ndetei ,Isodore S Obot. The association between alcohol dependence and depression before and after treatment for alcohol dependence. ISRN Psychiatry; 2012.1-6

[16] Benegal V, Gururaj G, Murthy P (2002). Project report on a WHO multi centre collaborative project: on establishing and monitoring alcohol's involvement in casualties;2000-2001.Accessed from http://www.nimhans.kar.nic.in/Deaddiction/lit/

[17] Sofia S Fedorova. Prevalence of anxiety and depression among alcohol dependent patients. [Dissertation].Moscow State Medical University: 2013.

[18] Brucee et al. Influence of psychiatric co morbidity on recovery and recurrence in generalized anxiety disorder, social phobia, and panic disorder, a 12-year prospective study. American Journal of Psychiatry. 2005; 162: 1179-1187. [PMed: 15930067].

[19] Sringeri SKR, Rajkumar RP, Muralidharan K, Chandrashekar CR, Benegal V (2008). The association between attention-deficit/hyperactivity disorder and early-onset alcohol dependence: a retrospective study. Indian Journal of Psychiatry;50: 262-5

[20] Wills TA, Sandy JM, Yaeger A, Shinar O (2001). Family risk factors and adolescent substance use: moderation effects for temperament dimensions. .Developmental Psychology; 37: 283-297. 


\section{International Journal of Science and Research (IJSR) \\ ISSN (Online): 2319-7064}

Index Copernicus Value (2015): 78.96 | Impact Factor (2015): 6.391

[21] Rhem et al. Global burden of diseases and injury and economic cost attributable to alcohol use and alcohol use disorders. The Lancet; Jun 2009:373:2223-33.

[22] Gururaj G, Isaac M, Girish N (2005a). Mental Health, neurological and Substance abuse disorders, strategies towards a systems approach. In Rao S (Ed), Burden of Disease in India. National Commission on Macroeconomics and Health, Ministry of Health and Family Welfare, Government of India, New Delhi.

[23] Gururaj G, Girish N, Benegal V (2006a). Alcohol control series 1: Burden and socio-economic impact of alcohol - The Bangalore Study. New Delhi: World Health Organisation, Regional Office for South East Asia.

[24] Sarkar AP, Sen S, Mondal S, Singh OP, Chakraborty A, Swaika B. A study on socio-demographic characteristics of alcoholics attending the de-addiction centre at Burdwan medical college and hospital in West Bengal. Indian J Public Health 2013; 57:33-5.

[25] Hazarika NC , Biswas D , Phukan RK , Hazarika D, Mahantha J. Prevalence \& pattern of substance abuse at Bandardewa, a border area of Assam \& Arunachal Pradesh. Indian Journal of Psychiatry.2000; 42(3):262266.

[26] Meena P K, Vohra AK. Prevalence and pattern of alcohol and substance abuse in urban areas of Rohtak city. Indian J Psychiatry. 2002; 44:348-52.

[27] Chaturvedi HK, Phukan RK, Mahantha J. The association of selected socio demographic factors \& differences in patterns of substance use: A pilot study in selected areas of northeast India. Substance use and misuse. 2003; 38(9):1305-1322.

Volume 6 Issue 1, January 2017

www.ijsr.net 